OPEN ACCESS

Edited by:

Silvia Fossati,

Lewis Katz School of Medicine, Temple University, United States

Reviewed by: Eszter Farkas,

University of Szeged, Hungary Julien Rossignol, Central Michigan University, United States

*Correspondence: Cheryl A. Hawkes cheryl.hawkes@open.ac.uk

Received: 15 March 2019 Accepted: 20 June 2019 Published: 04 July 2019

Citation:

Nizari S, Carare RO, Romero IA and Hawkes CA (2019) 3D Reconstruction of the Neurovascular Unit Reveals Differential Loss of Cholinergic Innervation in the Cortex and Hippocampus of the Adult Mouse Brain. Front. Aging Neurosci. 11:172. doi: 10.3389/fnagi.2019.00172

\section{D Reconstruction of the Neurovascular Unit Reveals Differential Loss of Cholinergic Innervation in the Cortex and Hippocampus of the Adult Mouse Brain}

\author{
Shereen Nizari ${ }^{1}$, Roxana O. Carare ${ }^{2}$, Ignacio A. Romero ${ }^{1}$ and Cheryl A. Hawkes ${ }^{1 *}$ \\ ${ }^{1}$ School of Life, Health and Chemical Science, Faculty of Science, Technology, Engineering and Mathematics, The Open \\ University, Milton Keynes, United Kingdom, ${ }^{2}$ Clinical and Experimental Sciences, Faculty of Medicine, University of \\ Southampton, Southampton, United Kingdom
}

Increasing evidence supports a role for cerebrovasculature dysfunction in the etiology of Alzheimer's disease (AD). Blood vessels in the brain are composed of a collection of cells and acellular material that comprise the neurovascular unit (NVU). The NVU in the hippocampus and cortex receives innervation from cholinergic neurons that originate in the basal forebrain. Death of these neurons and their nerve fibers is an early feature of $A D$. However, the effect of the loss of cholinergic innervation on the NVU is not well characterized. The purpose of this study was to evaluate the effect of the loss of cholinergic innervation of components of the NVU at capillaries, arteries and veins in the hippocampus and cortex. Adult male C57BL/6 mice received an intracerebroventricular injection of the immunotoxin p75NTR mu-saporin to induce the loss of cholinergic neurons. Quadruple labeling immunohistochemistry and 3D reconstruction were carried out to characterize specific points of contact between cholinergic fibers and collagen IV, smooth muscle cells and astrocyte endfeet. Innate differences were observed between vessels of the hippocampus and cortex of control mice, including a greater amount of cholinergic contact with perivascular astrocytes in hippocampal capillaries and a thicker basement membrane in hippocampal veins. Saporin treatment induced a loss of cholinergic innervation at the arterial basement membrane and smooth muscle cells of both the hippocampus and the cortex. In the cortex, there was an additional loss of innervation at the astrocytic endfeet. The current results suggest that cortical arteries are more strongly affected by cholinergic denervation than arteries in the hippocampus. This regional variation may have implications for the etiology of the vascular pathology that develops in AD.

Keywords: neurovascular unit, cholinergic, Alzheimer's disease, cerebral amyloid angiopathy, cortex, hippocampus 


\section{INTRODUCTION}

The loss of cholinergic neurons in the basal forebrain and the areas innervated by their fiber projections is a hallmark of Alzheimer's disease (AD; Whitehouse et al., 1982; Francis et al., 1999). Decreased cholinergic innervation of the hippocampus and cortex is associated with memory impairment (Damasio et al., 1985), decreased mini-mental state examination scores and behavioral changes (Perry, 1980; Tong and Hamel, 1999; GarciaAlloza et al., 2005). Moreover, acetylcholinesterase inhibitors (AChEIs) are currently one of only two approved drugs for the treatment of AD (Hampel et al., 2018). Recent studies have demonstrated that loss of basal forebrain gray matter occurs before the onset of clinical symptoms (Schmitz and Nathan Spreng, 2016) and that administration of the AChEI Donepezil during the prodromal stage of $\mathrm{AD}$ prevented basal forebrain degeneration (Cavedo et al., 2017). This highlights the significance of cholinergic neurotransmission in $\mathrm{AD}$.

Numerous experimental models have been used to mimic the loss of basal forebrain cholinergic neurons and their fiber projections. These include injection of ibotenic acid into the substantia innominata (Vaucher and Hamel, 1995), lesioning of the fimbria fornix (van der Staay et al., 1989) and electric pulse ablation of the medial septum (Scheiderer et al., 2006; Nelson et al., 2014). However, these models can result in widespread degeneration that may not specifically target cholinergic cell populations. The discovery that cholinergic neurons in the basal forebrain express the p75 neurotrophin receptor (NTR), while other populations of cholinergic neurons do not (Steininger et al., 1993), allowed for the development of targeted immunotoxins such as 192 IgG-saporin and its mouse analog, mu-p75-saporin. In vivo administration of mu-p75-saporin has been shown to selectively kill cholinergic neurons in the medial septum, horizontal and diagonal bands of Broca and nucleus basalis of Meynert and cause withdrawal of cholinergic projections in the cortex and hippocampus in mice (Berger-Sweeney et al., 2001; Hunter et al., 2004; Hamlin et al., 2013; Kerbler et al., 2013; Laursen et al., 2013; Ramos-Rodriguez et al., 2013). Although recent genetically-driven technologies such as optogenetics and designer receptor exclusively activated by designer drug (DREDD) have led to more targeted approaches to silence specific cholinergic populations (Hangya et al., 2015; Zhang et al., 2017), it is not clear if these techniques replicate the loss of cholinergic innervation that is seen in AD.

In addition to early loss of cholinergic neurons, increasing evidence suggests that alterations of the cerebrovasculature contribute to the etiology and/or progression of $\mathrm{AD}$. In fact, vascular pathology has been suggested to be the earliest indicator of the development of AD (Jack et al., 2010; Iturria-Medina et al., 2016). The most common form of cerebrovascular pathology associated with $\mathrm{AD}$ is cerebral amyloid angiopathy (CAA). CAA is defined as the presence of $\beta$-amyloid $(A \beta)$ deposits in the walls of cerebral blood vessels (Vinters, 1987) and is believed to develop due to an age-related failure of clearance of $A \beta$ from the brain. CAA develops principally in cortical and leptomeningeal arteries, with additional capillary involvement in individuals carrying the apolipoprotein E4 (apoE4) allele (Thal et al., 2008). It is observed least frequently in veins. Topographically, CAA starts in blood vessels of neocortical areas (e.g., occipital and parietal lobe), while subcortical vessels (e.g., hippocampus, thalamus) are typically not affected until later stages of the disease (Thal et al., 2008; Vinters and Gilbert, 1983). The reasons underlying the development of CAA and its pattern of distribution are currently unknown.

Blood vessels in the brain are composed of endothelial cells, basement membrane proteins, pericytes, smooth muscle cells, astrocytes and neurons that are collectively referred to as the neurovascular unit (NVU; Iadecola, 2017). The NVU is also a target of cholinergic innervation, which can occur at multiple sites, including astrocytes, smooth muscle cells and endothelial cells (Vaucher and Hamel, 1995). This innervation is important for the maintenance of vascular tone and in mediating site-directed blood flow via neurovascular coupling (Hamel, 2006). Loss of cholinergic contact with blood vessels has been reported in the cortex of AD brains (Tong and Hamel, 1999) and in transgenic mouse models of AD (Kuznetsova and Schliebs, 2013; Michalski et al., 2017). However, most of these studies have been carried out using 2D images and have focused on specific brain regions and/or selected vessels. Thus, the impact of the loss of cholinergic innervation on the entire NVU is not well characterized.

In this study, the mu-p75-saporin saporin model was used to induce death of basal forebrain cholinergic neurons and their fiber projections. Quadruple labeling immunohistochemistry and $3 \mathrm{D}$ reconstruction were carried out to characterize specific points of contact between cholinergic fibers and various components of the NVU and to compare this pattern between the cortex and the hippocampus.

\section{MATERIALS AND METHODS}

\section{Animals}

Eight- to ten-week-old male C57BL/6 mice were obtained from The Open University (OU, Milton Keynes, UK) or the University of Southampton (Southampton, UK) and were kept on a $12 \mathrm{~h}$ light/dark cycle with access to food and water ad libitum. Experiments were carried out in compliance with guidelines of the Animal Welfare and Ethics Research Boards at the Open University and the University of Southampton and with approval from the Home Office (PPL 70/8507; PPL 30/3095).

\section{Intracerebroventricular Injections}

Mice were anesthetized under isoflurane gas and placed into a stereotaxic frame (Kopf instruments, CA, USA). Topical anesthetic (Cryogesic, Acorus Therapeutics Limited Chester, UK) was applied to the scalp before the head was shaved. A midline incision was made and the skull cleaned. A small burr hole was drilled over the left and right lateral ventricles and $0.5 \mu \mathrm{L}$ of mu-saporin $(0.596 \mu \mathrm{g} / \mu \mathrm{L}$, Advanced Targeting Systems, San Diego, CA, USA; $n=16)$ or $0.9 \%$ saline $(n=19)$ was injected into each ventricle (coordinates from Bregma: $\mathrm{AP}=-0.4 \mathrm{~mm}, \mathrm{ML}=1.0 \mathrm{~mm}, \mathrm{DV}=-2.3 \mathrm{~mm}$ ) at a rate of $0.2 \mu \mathrm{l} / \mathrm{min}$ using a $32 \mathrm{G}$ Hamilton syringe. The needle was left in situ for 2 min after the injection to allow for 
diffusion. Analgesia was administered intraperitoneally at the time of surgery (Carprieve, 5\% w/v, $0.32 \mathrm{ml} / \mathrm{kg}$, Norbrook, Northamptonshire, UK) and mice were able to self-administer sugar-free jelly (Hartley, Histon Sweet Spreads Limited, Leeds, UK) containing Carprofen (250 $\mu \mathrm{g}$, Zoetis, London, UK) for 1 week post-surgery.

\section{Tissue Processing}

All mice were perfused intracardially with $0.01 \mathrm{M}$ phosphate buffered saline (PBS, pH 7.4) 45 days after surgery. For Western blots, brains were immediately dissected and snap frozen on dry ice and stored at $-80^{\circ} \mathrm{C}$. For immunohistochemistry, mice were perfused with $4 \%$ paraformaldehyde, the brains were post-fixed overnight and left in 30\% sucrose for 1 week. Brains were cryosectioned at $20 \mu \mathrm{m}$ thickness and collected as free-floating coronal sections and stored in anti-freeze storage solution $(30 \%$ glycerol, $30 \%$ ethylene glycol, $40 \% 0.01 \mathrm{M} \mathrm{PBS}$ ) at $-20^{\circ} \mathrm{C}$.

\section{Western Blotting}

Tissues from control $(n=8)$ and saporin-treated mice $(n=6)$ were homogenized in Ripa lysis buffer $[20 \mathrm{mM}$ Tris- $\mathrm{HCl}(\mathrm{pH}$ 8.0), $150 \mathrm{mM} \mathrm{NaCl}, 1 \mathrm{mM}$ EDTA, $0.1 \%$ SDS, 1\% Igepal, $50 \mathrm{mM} \mathrm{NaF}, 1 \mathrm{mM} \mathrm{NaVO}$ ] containing a protease inhibitor cocktail (Merck Millipore, Watford, UK), spun down $(13,000 \mathrm{~g}$, 10 mins, $4^{\circ} \mathrm{C}$ ) and supernatants collected, aliquoted and frozen at $-80^{\circ} \mathrm{C}$ until further use. Proteins $(30 \mu \mathrm{g})$ were separated by gel electrophoresis on $4 \%-20 \%$ Tris-acetate gels (Fisher Scientific) and transferred onto a nitrocellulose membrane. Membranes were incubated overnight at $4^{\circ} \mathrm{C}$ with anti-choline acetyltransferase (ChAT, 1:500, Merck Millipore), stripped and re-probed with anti-glyceraldehyde-3-phosphate dehydrogenase (GAPDH, 1:50,000, Sigma-Aldrich, Dorset, UK) antibody to ensure equal protein loading. Two blots were replicated for each brain region. Immunoblots were quantified by densitometry using Image J software (NIH, MD, USA) and calculated as an optical density ratio of protein levels normalized to GAPDH levels.

\section{Immunohistochemistry}

For single-labeling immunohistochemistry of cholinergic cell bodies and fibers, tissue sections were washed in 0.01 M PBS, blocked with 15\% normal donkey serum (NDS; Sigma-Aldrich) and incubated overnight with either anti-ChAT (1:100) or anti-laminin (1:350, Sigma-Aldrich), after pre-treatment with pepsin $\left(1 \mathrm{mg} / \mathrm{mL}\right.$ in $0.2 \mathrm{~N} \mathrm{HCl}, 30 \mathrm{~s}$ at $\left.37^{\circ} \mathrm{C}\right)$. The next day, sections were washed in PBS and incubated for $2 \mathrm{~h}$ at room temperature with anti-donkey AlexaFluor 488 (Fisher Scientific, Loughborough, UK). For quadruple labeling of the NVU, sections were treated with pepsin, incubated overnight with anti-ChAT (1:100), washed in PBS and incubated with anti-goat AlexaFluor 555. After washing in PBS, sections were incubated simultaneously with anti-collagen IV (1:100, Abcam, Cambridge, UK), anti- $\alpha$ smooth muscle actin ( $\alpha$-SMA)-FITC (1:350, SigmaAldrich) and anti-glial fibrillary protein (GFAP, 1:500, Abcam). Sections were then developed with anti-rabbit AlexaFluor 405 and anti-chicken AlexaFluor 633 (1:200, Fisher Scientific). All fluorescent sections were coverslipped using Mowiol ${ }^{\circledR}$ (Sigma-Aldrich) containing $0.1 \% \mathrm{v} / \mathrm{v}$ Citifluor (Citifluor Limited, London, UK) mounting media.

\section{Image Acquisition and Analysis}

Coronal brain sections were imaged with an SP5 Leica scanning laser confocal microscope. Low magnification images of the cortex and hippocampus were stitched together using Image software (NIH, MD, USA). The density of neuronal cell bodies, fibers and blood vessels in each region of interest was quantified by calculating the percentage area covered by staining using ImageJ software. NVUs in the hippocampus and cortex were imaged using the $\times 100$ oil immersion objective, using $z$ stacks with $\leq 2 \mu \mathrm{m}$ spacing between slices. Images were deconvolved and converted into Imaris-compatible files using AutoQuant X3 version X3.0.4 software (MediaCybernetics Inc., Rockville, MD, USA).

\section{D Reconstruction of the NVU}

To quantify the parameters of each component of the NVU, deconvolved images were processed using Imaris software (Bitplane ${ }^{\circledR}$ ) and surfaces were created for each component of the NVU. For each vessel, the following measurements were acquired: the total area of a selected surface $\left(\mu \mathrm{m}^{2}\right)$, the volume of a selected surface $\left(\mu \mathrm{m}^{3}\right)$, the length of the vessel imaged $(\mu \mathrm{m})$ and the average diameter of the vessel $(\mu \mathrm{m})$. The total area of contact between two selected surfaces (e.g., ChAT nerve fibers contacting collagen IV) was calculated using the Imaris Xtension "Surface to Surface Contact Area" (Imaris V8.31, ImarisXT Bitplane Inc created by Matthew J Gastinger, Bitplane). Only surfaces that made direct contact with each other (i.e., $0 \mu \mathrm{m}$ apart) were quantified. Vessels were classified as capillaries if they were $\leq 10 \mu \mathrm{m}$ in diameter, arteries were identified as having a diameter of $>10 \mu \mathrm{m}$ and positive for SMA, while veins were identified as having a diameter $>10 \mu \mathrm{m}$ but lacking SMA. A total of five capillaries, five arteries and three veins were quantified for each mouse ( $n=7-11$ control, $n=6-10$ saporin) per brain region and the average values per mouse were used for statistical analysis.

\section{Statistical Analysis}

Data were tested for normality using the Kolmogorov-Smirnov test. For normally distributed data, comparisons between two groups were carried out using two-tailed Student's $t$-test. Where there were more than two groups, one-way or two-way repeated measures ANOVA was used followed by Sidak's post hoc. The ROUT test was used to identify and exclude any outliers. For data that were not normally distributed, the Mann-Whitney $U$ test or Kruskal-Wallis test with Dunn's post hoc test was used. Data represents mean \pm SEM and $p<0.05$ was considered to be statistically significant. Analysis was carried out using GraphPad Prism software.

\section{RESULTS}

\section{Cholinergic Loss in the Medial Septum, Hippocampus and Cortex Following Administration of Mu-Saporin}

As shown in Figure 1, ChAT-positive cholinergic neurons were observed in the medial septum, diagonal band of Broca, 

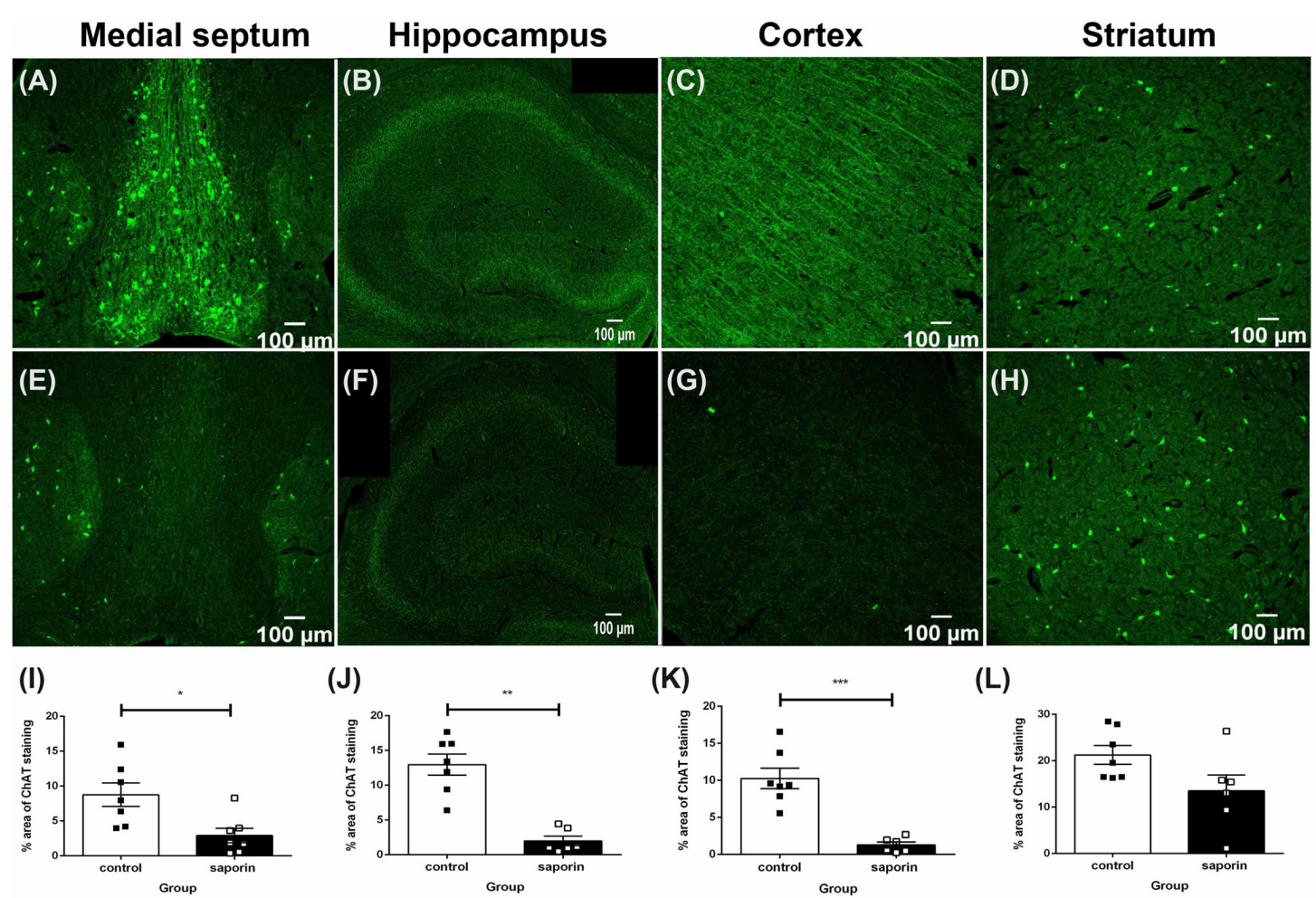

(L)

(M)

Hippocampus

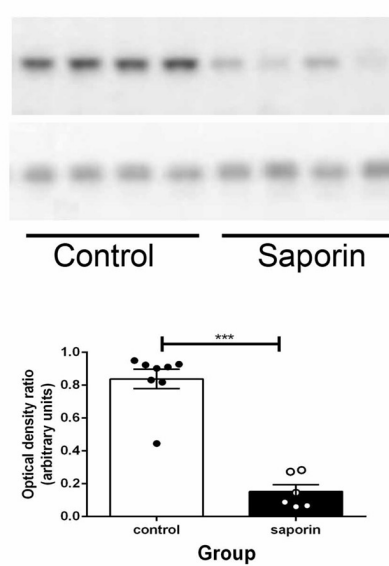

(N)

Cortex

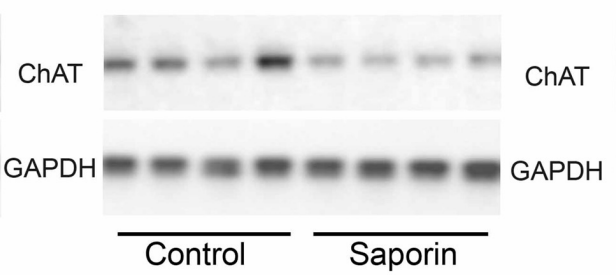

(0)

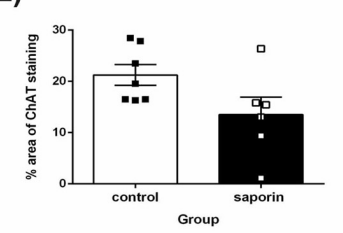

Striatum
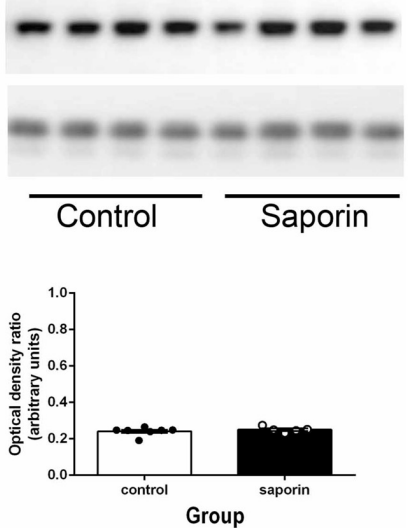

FIGURE 1 | Loss of cholinergic neurons and fiber projections following administration of mu-p75-saporin. (A-H) Photomicrographs of choline acetyltransferase (ChAT)-positive neurons and fibers in the medial septum (A,E), hippocampus (B,F), cortex (C,G) and striatum (E,H) in control (A-D) and saporin-treated (E-H) mice. (I-L) Quantification of the percent area covered by ChAT-positive staining in control and saporin-treated mice in the medial septum (I), hippocampus (J) and cortex (K). p75-negative cholinergic neurons in the striatum were not affected by saporin treatment (L). (M-O) Western blotting confirmed a significant loss of ChAT protein expression in the hippocampus (M) and cortex (N) after saporin administration, while ChAT levels in the striatum did not differ between control and treated mice (0). Data represent mean \pm SEM. ${ }^{*} p<0.05,{ }^{* *} p<0.01,{ }^{* * *} p<0.001$, two-tailed Student's $t$-test. Scale bar $=100 \mu \mathrm{m}$.

nucleus basalis of Meynert and in the striatum of control mice. Cholinergic fiber projections were also observed in the hippocampus (Figure 1B) and cortex (Figure 1C). Significantly less ChAT staining was detected in the medial septum of saporintreated mice at 45 days post-surgery (Figures 1E,I). This was accompanied by a significant decrease in cholinergic nerve fiber density in the hippocampus (Figures 1F,J) and the cortex (Figures 1G,K). As expected, p75 NTR-negative neurons in the striatum were not affected by saporin treatment (Figures 1H,L). Western blotting confirmed a significant decrease in ChAT 

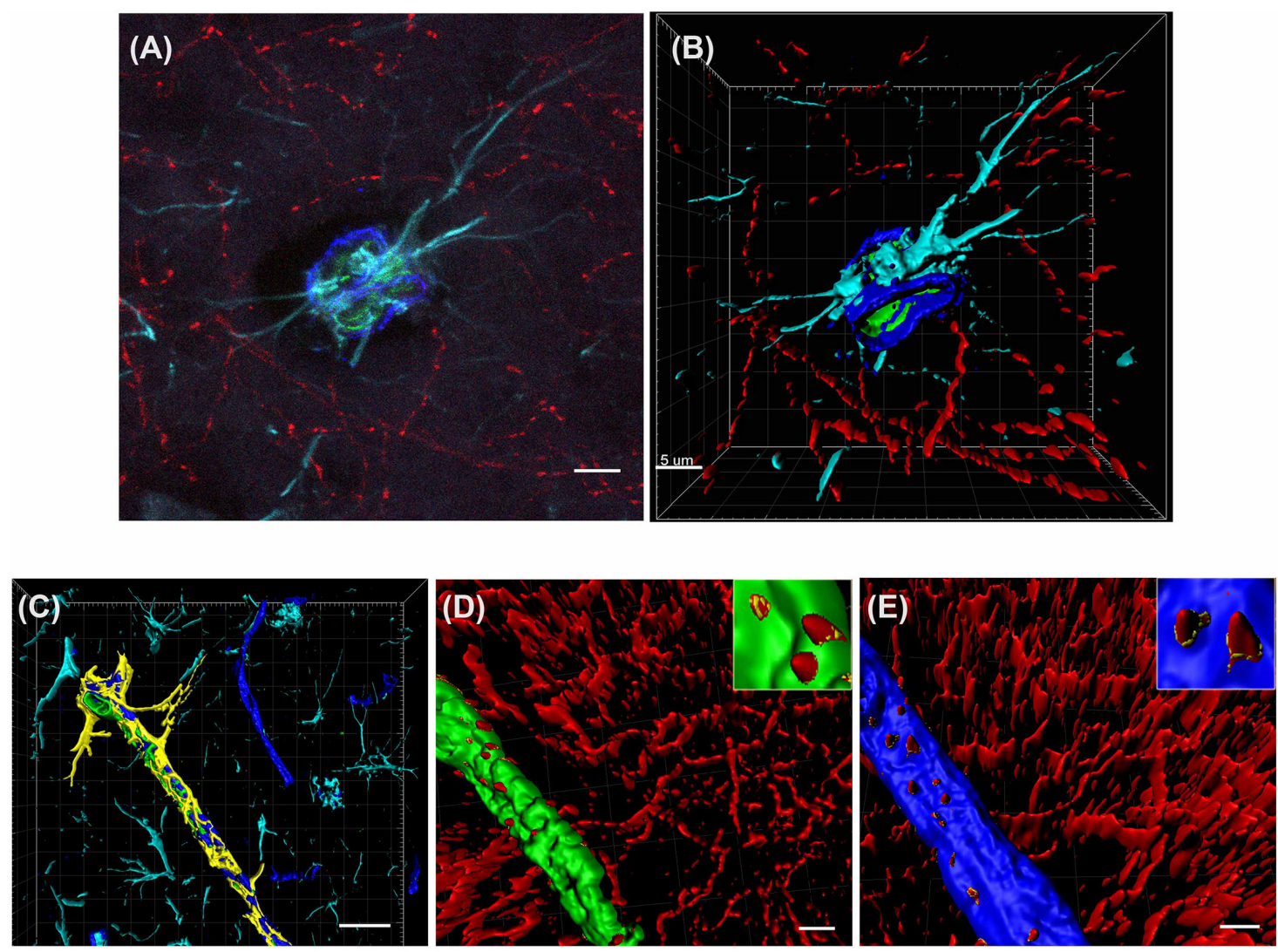

FIGURE 2 | 3D reconstruction of the neurovascular unit (NVU). (A,B) Photomicrograph (A) and 3D reconstruction (B) of an artery stained for collagen IV (dark blue), smooth muscle actin (SMA; green), astrocytes (turquoise) and cholinergic nerve fibers (red). (C-E) Yellow outlines indicate the surfaces created for each of the NVU components. Examples are shown for surface area contact between perivascular astrocytes and collagen IV (C), contact of cholinergic nerve fibers to smooth muscle cells (D, yellow outlines in inset) and contact of cholinergic nerve fibers to collagen IV (E, yellow outlines in inset). Scale bar $(\mathbf{A}, \mathbf{B}, \mathbf{D}, \mathbf{E})=5 \mu \mathrm{m}, \mathbf{( C )}=20 \mu \mathrm{m}$.

protein levels in the hippocampus (Figure $\mathbf{1} \mathbf{M}$ ) and cortex (Figure 1N) following saporin administration and no difference in ChAT expression between control and saporin-treated mice in the striatum (Figure 10).

\section{Characterization of Cholinergic Loss at the NVU in the Hippocampus and Cortex}

Cholinergic nerve fibers are known to innervate blood vessels in the hippocampus and cortex (Vaucher and Hamel, 1995). To characterize the precise effects of saporin treatment at the NVU, quadruple-labeling immunohistochemistry was used to label cholinergic fibers and three components of the NVU-collagen IV-positive basement membranes, smooth muscle cells and astrocytes (Figure 2A). Confocal images of the vessels were then reconstructed using $3 \mathrm{D}$ modeling software and surfaces were created for each of the four proteins (Figures 2B-E). The surface area of ChAT contact with each component of the NVU (standardized to vessel length) was analyzed across capillaries, arteries/arterioles and veins/venules from control and saporintreated mice.

At the basement membrane of vessels in the hippocampus, saporin treatment induced a decrease in the amount of contact between cholinergic nerve fibers and collagen IV at capillaries, arteries and veins (Figures $\mathbf{3 A - F}$ ), although this decrease was only statistically significant at arteries (Figure 3G). In the cortex, cholinergic innervation of the basement membrane did not differ between control and saporin-treated mice at capillaries and veins but was significantly decreased at the arteries of saporin-treated mice (Figures $\mathbf{3 H}-\mathbf{N}$ ). No differences were noted between control and saporin-treated mice at any vessel type in the striatum (Supplementary Figure S1A).

Analysis of perivascular innervation at the smooth muscles of arteries found that there was a significant decrease in the surface area contact between ChAT and $\alpha$-SMA in saporintreated in both the hippocampus (Figures $\mathbf{4 A - C}$ ) and the cortex (Figures 4D-F), while the striatum was not affected (Supplementary Figure S1B).

Quantification of ChAT contact with perivascular astrocytes in the hippocampus revealed no difference in the amount of contact with GFAP-positive astrocytes between control and saporin-treated mice in any vessel type (Figures 5A-G). By contrast, significantly less ChAT contact was observed at arteries in the cortex of saporin-treated mice compared to control animals (Figures $\mathbf{5} \mathbf{H}-\mathbf{N}$ ). No differences were 


\section{Hippocampus}
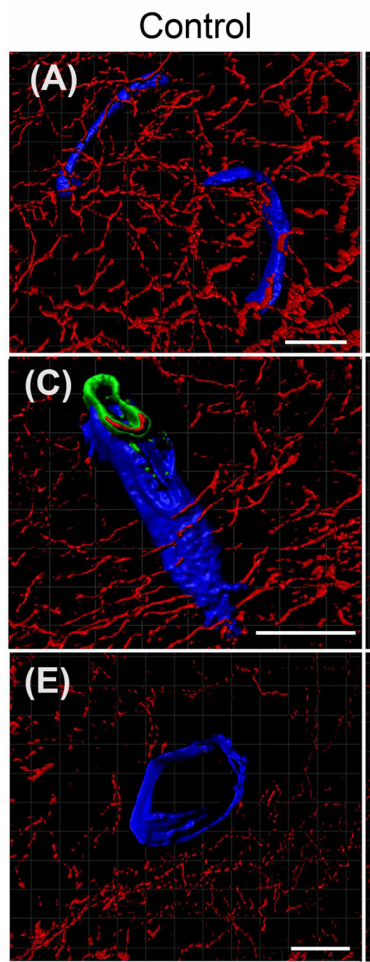

(G)

Cholinergic nerve fibre contact to collagen IV

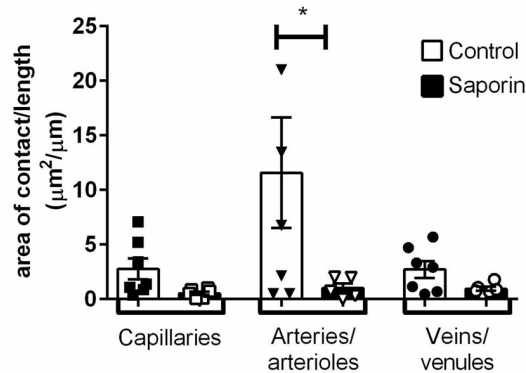

\section{Cortex}
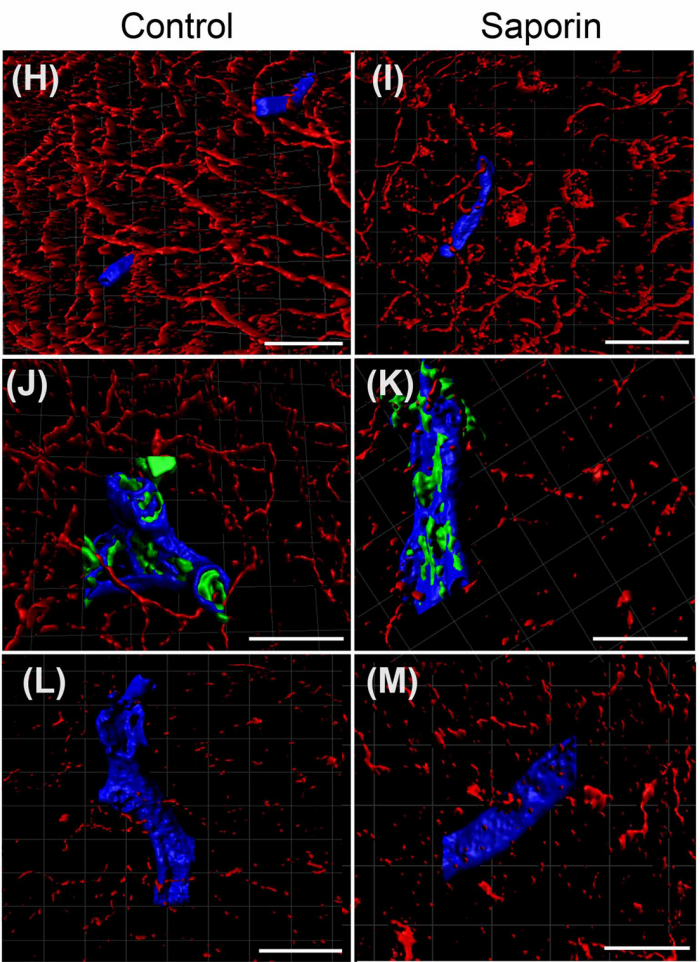

(N)

Cholinergic nerve fibre contact to collagen IV

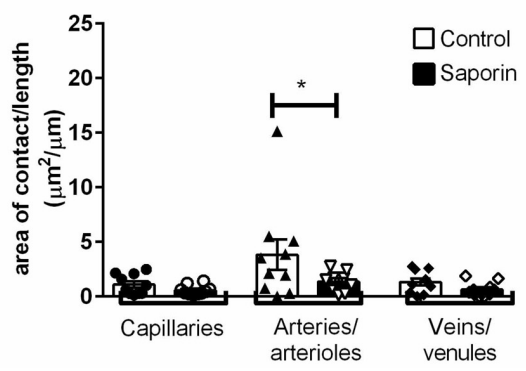

FIGURE 3 | Perivascular cholinergic contact at the basement membrane. (A-M) Representative images of the 3D reconstruction of the NVU in capillaries (A,B,H,I) arteries (C, D,J,K) and veins (E,F,L,M) in the hippocampus (A-F) and cortex (H-M) of control (A,C,E,H,J,L) and saporin-treated mice (B,D,F,I,K,M). ChAT-positive fibers are shown in red, collagen IV is shown in blue and SMA is shown in green. (G,N) Quantification of the surface area of contact between ChAT-positive fibers and collagen IV demonstrated a significant decrease in contact at the arteries of saporin-treated animals in both the hippocampus (G) and cortex (N). Data represent mean \pm SEM. ${ }^{*} p<0.05$, two-way ANOVA with Sidak's post hoc test. Scale bars $=20 \mu \mathrm{m}$.

observed between control and saporin mice at cortical capillaries or veins (Figures $\mathbf{5} \mathbf{H}-\mathbf{N}$ ) or between control and saporin-treated mice at any vessel type in the striatum (Supplementary Figure S1C).

To determine if saporin induced changes in blood vessel density, the percent area covered by laminin-positive capillaries and large-diameter vessels were quantified in the cortex and hippocampus of control and saporin-treated mice (Figures 6A-E). In control mice, the density of both capillaries and arteries/veins was significantly higher in the cortex compared to the hippocampus (Figures 6A,B). No differences in vessel density were noted between control and saporin-treated mice in either brain region (Figure 6E).

\section{Regional Variation in Perivascular Innervation}

To determine if there were regional differences in endogeneous and saporin-induced cholinergic innervation, measurements of 


\section{Hippocampus}
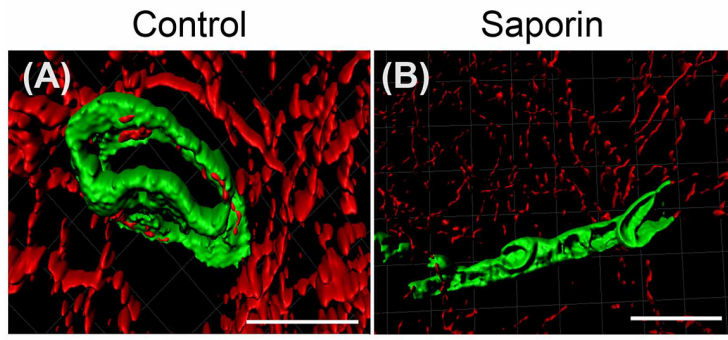

(C) Cholinergic nerve fibre contact to SMA

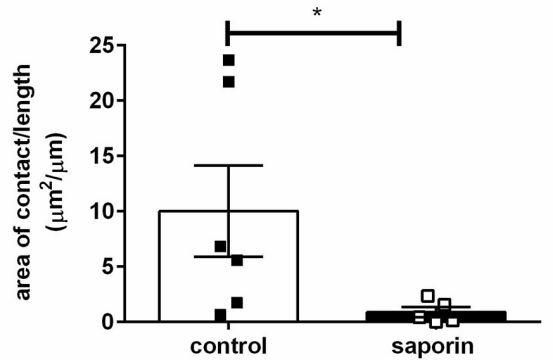

\section{Cortex}

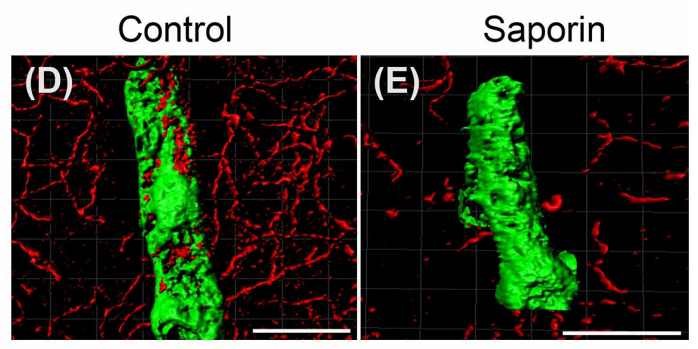

(F) Cholinergic nerve fibre contact to SMA

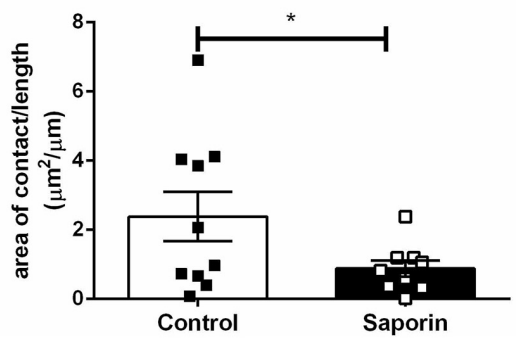

FIGURE 4 | Perivascular cholinergic contact at smooth muscle cells. (A-E) Representative images of the 3D reconstruction of the NVU in arteries in the

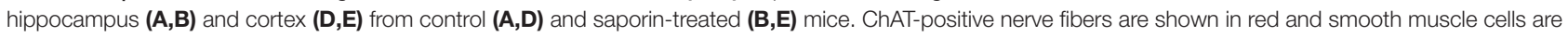
shown in green. (C,F) Quantification of the surface area of contact between ChAT-positive fibers and SMA demonstrated a significant decrease in contact in saporin-treated animals in both the hippocampus (C) and cortex (F). Data represent mean \pm SEM. ${ }^{*} p<0.05$, Mann-Whitney $U$ test (hippocampus) and one-tailed Student's t-test (cortex). Scale bars $=20 \mu \mathrm{m}$.

ChAT contact with components of the NVU were compared between the hippocampus and cortex. Quantification of overall cholinergic nerve fiber density was found to be significantly higher in the hippocampus compared to the cortex in control mice (Figure 7A). Following saporin treatment, this difference was lost (Figure 7B). The degree of cholinergic innervation at the basement membrane did not differ between the hippocampus and cortex at capillaries, arteries or veins of control (Figure 7C) or saporin-treated mice (Figure 7D). ChAT innervation of smooth muscle cells also did not differ between arteries in the hippocampus and cortex in either control (Figure 7E) or saporintreated mice (Figure 7F). However, perivascular astrocyte endfeet surrounding cortical capillaries in control mice received significantly less cholinergic input compared to astrocytes at the capillaries in the hippocampus (Figure 7G). Significantly less cholinergic input onto astrocyte endfeet was also noted at veins in the cortex of saporin-treated mice compared to hippocampal veins (Figure $7 \mathbf{H}$ ).

\section{Impact of Loss of Perivascular Innervation on Components of the NVU}

To determine if loss of cholinergic innervation induced changes in components of the NVU, the volume of collagen IV and smooth muscle cells as well as the area of astrocyte endfoot coverage was evaluated in vessels of control and saporin-treated mice. Comparisons between the cortex and hippocampus were also carried out.
As shown in Table 1, within the hippocampus, the volume of collagen IV was significantly higher in veins compared to capillaries in control mice. This relationship was maintained following saporin treatment. However, collagen IV volumes did not differ between control and saporin-treated mice in any vessel type. In the cortex, the volume of collagen IV was highest in arteries compared to capillaries and veins in both control and saporin-treated mice (Table 1). Regional comparisons including the striatum revealed that the volume of collagen IV was significantly higher in veins in the hippocampus than veins in the cortex and striatum in both control mice and those treated with saporin.

Analysis of smooth muscle volume found no significant difference between control and saporin mice in any brain region (Table 2). Similarly, no significant differences in smooth muscle volume were noted between the cortex, hippocampus or striatum in either treatment group (Table 2).

Finally, analysis of perivascular astrocyte coverage of hippocampal vessels revealed a significantly higher amount of endfoot contact in veins compared to capillaries in control animals (Table 3). Following saporin administration, astrocyte coverage remained significantly higher in hippocampal veins compared to both capillaries. No differences in perivascular astrocyte coverage were noted between vessel types in the cortex in either control or saporin-treated mice (Table 3). Comparison between vessels of the hippocampus, cortex and striatum found that astrocyte contact was lowest in all the 


\section{Hippocampus}
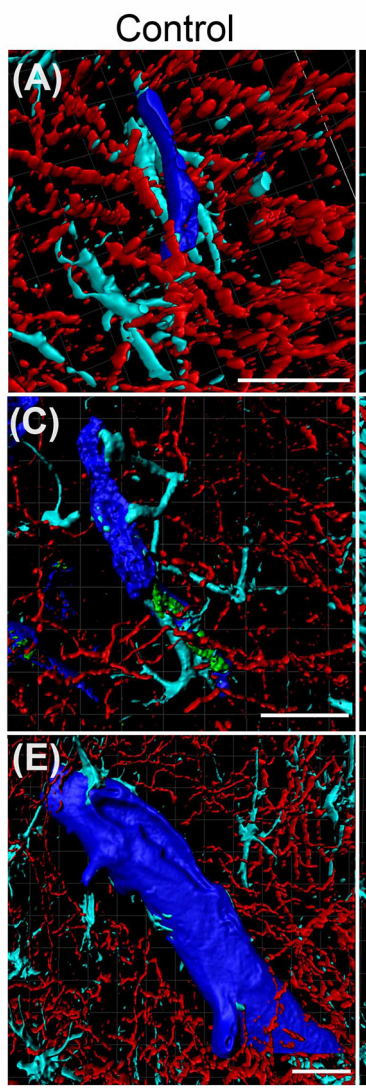

(G)

Cholinergic nerve fibre contact to perivascular astrocytes

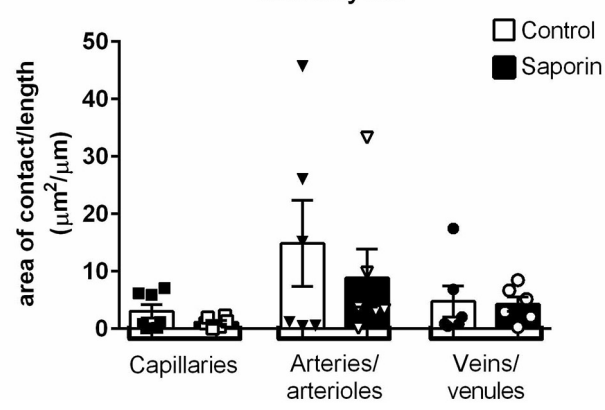

\section{Cortex}
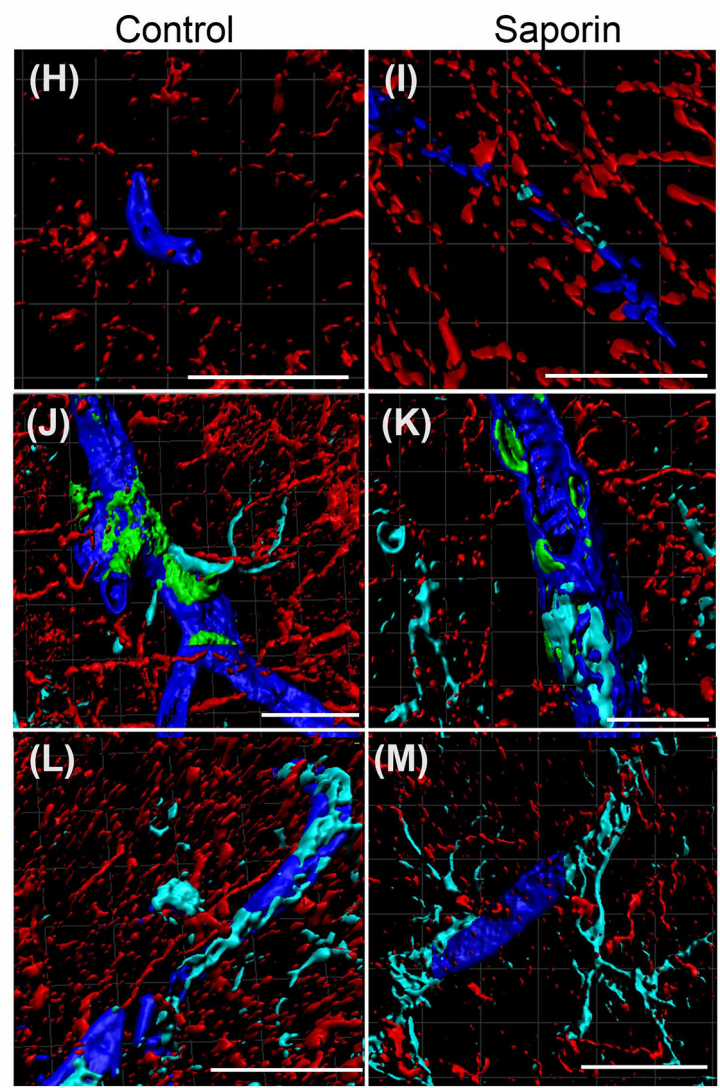

(N)

Cholinergic nerve fibre contact to perivascular astrocytes

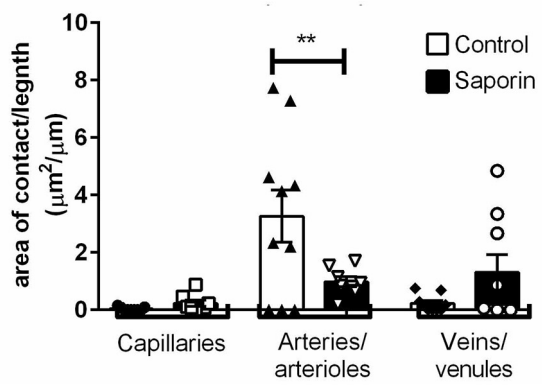

FIGURE 5 | Perivascular cholinergic contact at perivascular astrocytes. (A-M) Representative images of the 3D reconstruction of the NVU in capillaries (A,B,H,I), arteries (C, $\mathbf{D}, \mathbf{J}, \mathbf{K})$ and veins (E,F,L,M) in the hippocampus (A-F) and cortex (H-M) of control (A,C,E,H,J,L) and saporin-treated mice (B,,D,F,I,K,M). ChAT-positive fibers are shown in red, collagen IV is shown in blue, SMA is shown in green and glial fibrillary protein (GFAP) is shown in turquoise. (G,N) Quantification of the surface area of contact between ChAT-positive fibers and astrocyte endfeet found no differences between control and saporin-treated animals in any vessels of the hippocampus (G), but a significant decrease in contact at the arteries of saporin-treated animals the cortex (N). Data represent mean \pm SEM. $* * p<0.01$, two-way ANOVA with Sidak's post hoc test. Scale bars $=20 \mu \mathrm{m}$.

vessel types in the striatum. In addition, astrocyte coverage of veins in the hippocampus was approximately 10-fold higher compared to coverage of veins in the cortex and 100-fold higher than veins in the striatum in both control and saporin mice (Table 3).

\section{DISCUSSION}

Although the loss of cholinergic neurons in $\mathrm{AD}$ has been described extensively, the effect of this loss on the NVU is not well characterized. Moreover, previous studies that have 


\section{Hippocampus}
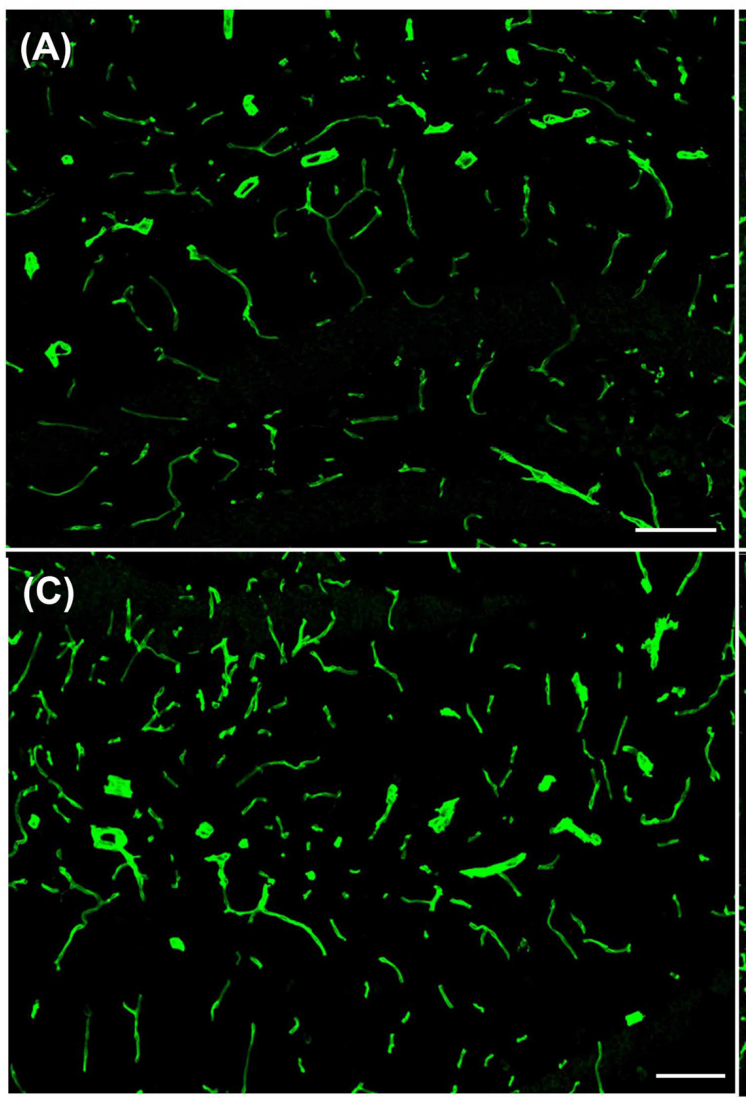

\section{Cortex}
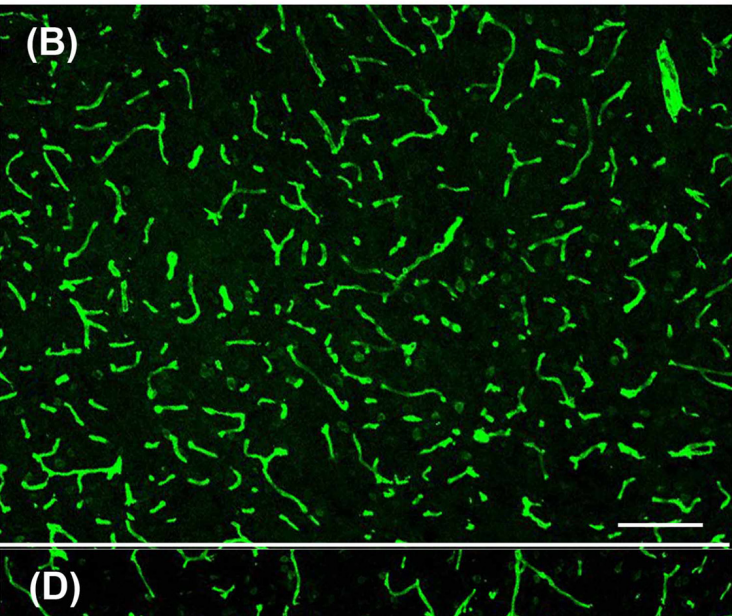

(D)

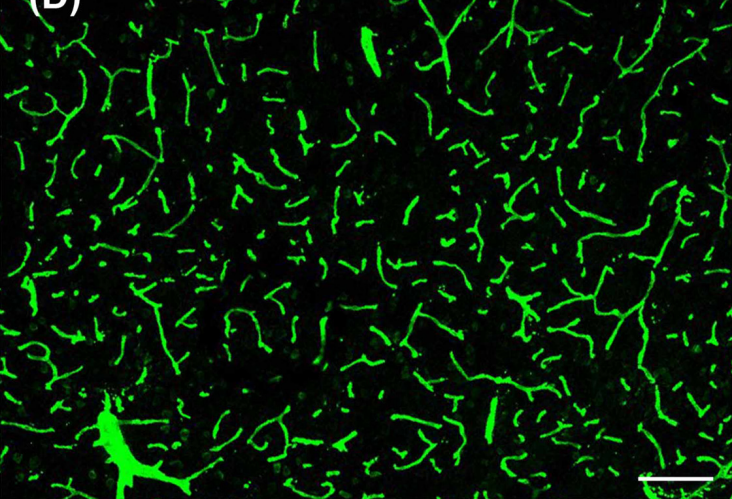

(E)

Vessel area coverage

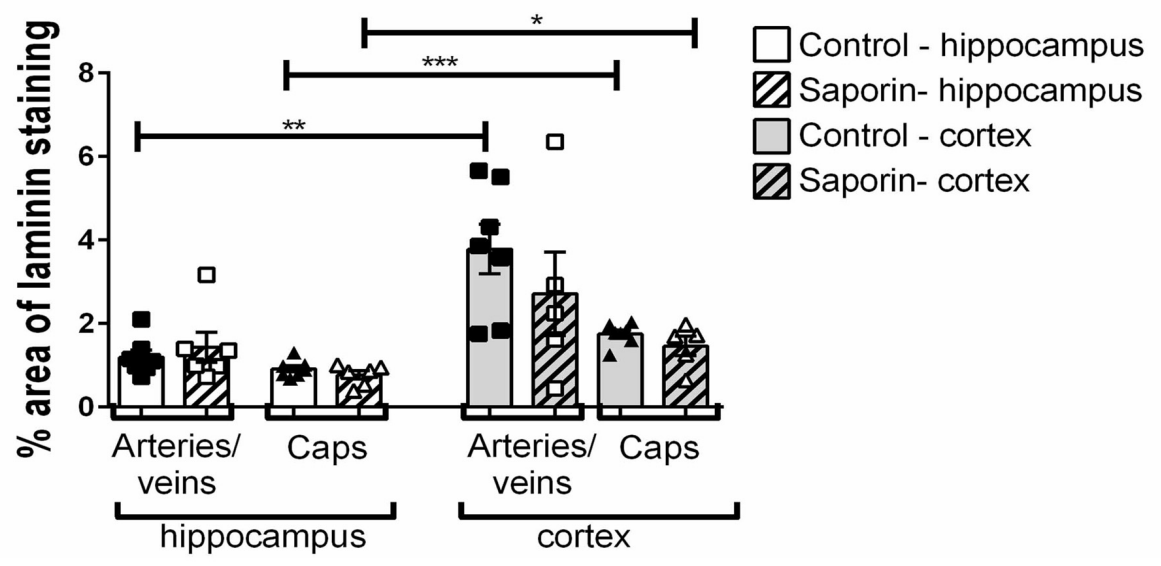

FIGURE 6 | Regional comparison of blood vessel density. (A-D) Photomicrographs of laminin-positive blood vessels in the hippocampus (A,C) and cortex (B,D) of control (A,B) and saporin-treated mice (C,D). (E) Quantification of the density of capillaries (caps) and large-diameter vessels in the hippocampus and cortex in treatment groups. Data represent mean \pm SEM. ${ }^{*} p<0.05,{ }^{* *} p<0.01$, ${ }^{* * *} p<0.001$, two-tailed Student's $t$-test. Scale bar $=100 \mu$ m.

looked at perivascular innervation by cholinergic nerve fibers have largely been carried out using $2 \mathrm{D}$ images obtained from double or triple labeling immunohistochemistry or by
immuno-EM (Itakura et al., 1977; Tong and Hamel, 1999; Kuznetsova and Schliebs, 2013). By combining quadruple labeling immunohistochemistry with $3 \mathrm{D}$ reconstruction, the 


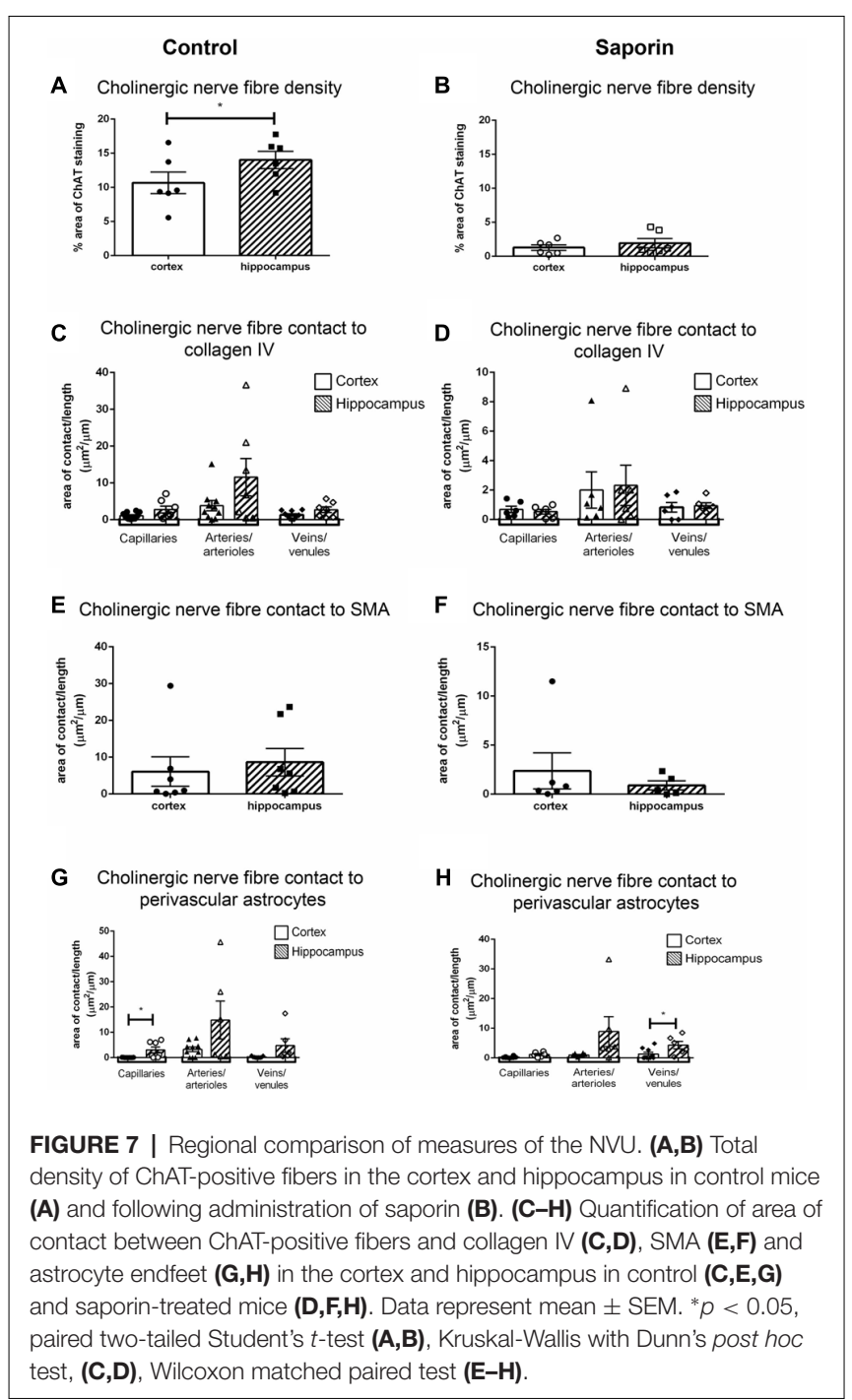

current study allowed not only for individual components of the NVU to be assessed under basal and pathological conditions but also for perivascular innervation to be quantified along multiple components of the NVU around the entire surface of the blood vessel.

We chose to use the saporin model of cholinergic denervation because of its well characterized ability to cause selective death of basal forebrain cholinergic neurons across many species, including mice, rats and non-human primates (Fine et al., 1997; Leanza, 1998; Lin et al., 1999; Berger-Sweeney et al., 2001; Lehmann et al., 2002; Birthelmer et al., 2003; Hawkes et al., 2005; Scheiderer et al., 2006; Ramos-Rodriguez et al., 2013). Such immunotoxin models are preferable to older lesioning models that can result in widespread, non-specific neuronal damage (van der Staay et al., 1989; Scheiderer et al., 2006; Nelson et al., 2014). On the other hand, the relatively rapid time course of death induced by saporin is unlikely to mimic the progressive loss of cholinergic neurons that is seen in $\mathrm{AD}$. More refined methods have been developed to silence basal forebrain cholinergic neurons using optogenetics and DREDD 
technologies (Shi et al., 2015; Chen et al., 2016). However, whether such techniques fully replicate the loss of cholinergic signaling, including withdrawal of trophic support and related inflammatory processes, that is observed in $\mathrm{AD}$ is not yet known. In the present study, administration of saporin led to a significant and specific loss of cholinergic neurons in the basal forebrain at 45 days post-surgery. The fiber projections from these neurons were also lost in the hippocampus and cortex. Other major populations of cholinergic neurons that do not express the p75NTR, including those in the striatum (Yeo et al., 1997) were not affected by saporin treatment.

Using 3D reconstruction of blood vessels, ChAT-positive fibers were found to innervate capillaries, arteries and veins in the hippocampus and cortex. As expected (Toribatake et al., 1997; Mulligan and MacVicar, 2004; Hamel, 2006; Hamilton et al., 2010; Chen et al., 2014), cholinergic innervation was observed at all levels of the NVU investigated, including the basement membranes, smooth muscle cells and perivascular astrocytes. The majority of the innervation was observed at arteries, in agreement with previous studies (Chédotal et al., 1994; Vaucher and Hamel, 1995; Luiten et al., 1996; Kuznetsova and Schliebs, 2013). Predominant targeting of arteries by cholinergic nerve fibers is perhaps unsurprising given the role of ACh in mediating neurovascular coupling (Hamel, 2006; Willis et al., 2006; Lecrux et al., 2017).

Increasing evidence suggests that there is heterogeneity of cells of the NVU, including pericytes and astrocytes, across both vessel type and brain regions (Shepro and Morel, 1993; Noumbissi et al., 2018). In the present study, we observed innate differences between vessels of the hippocampus and cortex. These included: (i) a significantly higher vessel density in the cortex; (ii) a higher overall ChAT fiber density in the hippocampus and more ChAT contact with perivascular astrocytes in hippocampal capillaries; (iii) thicker basement membrane in the veins of the hippocampus; and (iv) greater coverage of the basement membrane by astrocyte endfeet in hippocampal veins compared to veins in the cortex.

The observation that total cholinergic fiber density was higher in the hippocampus compared to the cortex is in agreement with previous reports (Kitt et al., 1994). However, given that vesssel density showed the opposite pattern, it is perhaps surprising that there was no difference in the amount of cholinergic innervation at blood vessels in the hippocampus vs. those in the cortex. It is possible that by only quantifying direct contact (e.g., $0 \mu \mathrm{m}$ distance) between ChAT fibers and basement membrane or smooth muscle cells, we have underestimated the potential degree of cholinergic innervation at the NVU, which has been classified in previous studies to be within $3 \mu \mathrm{m}$ from the basement membrane (Vaucher

TABLE 2 | Regional comparison of volume of smooth muscle cells in arteries.

\begin{tabular}{|c|c|c|c|}
\hline $\begin{array}{l}\text { SMA Volume/length } \\
\left(\mu \mathrm{m}^{3} / \mu \mathrm{m}\right) \pm \mathrm{SEM}\end{array}$ & Hippocampus & Cortex & Striatum \\
\hline Control & $60.02 \pm 10.6$ & $50.75 \pm 16.2$ & $65.88 \pm 19.7$ \\
\hline Saporin & $33.10 \pm 7.4$ & $39.54 \pm 9.0$ & $33.03 \pm 5.7$ \\
\hline
\end{tabular}

Values represent mean \pm SEM. No significant differences were noted (two-way repeated measures ANOVA with Sidak's post hoc test). 
and Hamel, 1995). Our findings that cholinergic contact with perivascular astrocyte endfeet tended to be higher in the hippocampus across all vessel types and was significantly higher at hippocampal capillaries compared to cortical capillaries, suggest that there may be functional differences between cortical and hippocampal vessels in their responsiveness to cholinergic signaling.

Astrocyte coverage of vessels was also observed to be higher in the hippocampus than the cortex, although this was only significant at veins. This is in keeping with the reported distribution of parenchymal GFAP-positive astrocytes (Emsley and Macklis, 2006). This finding was likely related to the observed greater thickness of collagen IV, given that astrocytes and endothelial cells are the main sites of basement membrane production (Baeten and Akassoglou, 2011). Expression of collagen IV has been shown to be significantly upregulated in capillaries and arteries during normal and in AD (Kalaria and Pax, 1995; Farkas and Luiten, 2001; Christov et al., 2008; Magaki et al., 2018). Thickening of the basement membrane and alterations in basement membrane composition has been hypothesized to precede the development of CAA (Wyss-Coray et al., 2000). However, veins are the vessel type least likely to be affected by CAA and CAA develops more slowly in vessels in the hippocampus than those in the cortex (Thal et al., 2008). It may be that increased basement thickness makes the veins in the hippocampus less likely to be deformed by pressure changes and thus helps to ensure a consistent cerebral perfusion (Zócalo et al., 2013; Thorin-Trescases et al., 2018) and to maintain a driving force for clearance of solutes in the cerebral spinal fluid (CSF) and/or interstitial fluid (ISF). In addition, the walls of veins are important for the egress of leukocytes from the blood into the brain in neurodegenerative diseases and this process requires that leukocytes enter a perivenular space bounded by endothelial and glia limitans basement membranes (Owens et al., 2008; Engelhardt et al., 2016). The variation in the degree of collagen IV and astrocyte coverage may reflect regional variability in the neuroinflammatory properties of the veins in the hippocampus compared to the cortex.

Saporin treatment significantly reduced the amount of cholinergic contact with the basement membrane of arteries in both the cortex and hippocampus, while capillaries and veins were unaffected. This may reflect the proportional endogeneous degree of cholinergic innervation between vessel types, which was highest in arteries. Regional differences were also observed in the degree of cholinergic loss at the NVU. While saporin treatment induced a loss of cholinergic innervation at the basement membrane and smooth muscle cells of arteries in both the hippocampus and cortex, there was additional loss of cholinergic contact of astrocyte endfeet in cortical arteries. The reason for this variability is unknown. It may be that cholinergic supply of the cortical astrocytes is important for their function in the convective influx/glymphatic entry of CSF along the pial glial basement membranes (Albargothy et al., 2018). Recent 3D mapping studies have shown that the dendritic arbors of basal forebrain neurons that project to the cortex differ from those that project to the hippocampus in that single cortical dendrites innervate large areas of the neuropil (Wu et al., 2014; Li et al., 2018). It is possible that a similar pattern of innervation exists at blood vessels in the cortex such that the loss of one dendritic arbor affects multiple vessels. This may also be related to the lower endogeneous level of contact between cholinergic nerves and astrocytes in the cortex, which may make cortical vessels more susceptible than those in the hippocampus to loss of cholinergic innervation.

Each of the NVU components studied have been shown to play a role in mediating the clearance of $A \beta$ from the brain. Cerebrovascular basement membranes act as conduits along which $\mathrm{A} \beta$ contained within CSF and ISF is removed from the brain (Iliff et al., 2012; Hawkes et al., 2013; Morris et al., 2014; Albargothy et al., 2018). Smooth muscle cells express low-density receptor related protein-1 (LRP-1) which mediates cellular uptake of $\mathrm{A} \beta$ and its transcytosis across the blood brain barrier (BBB; Kanekiyo et al., 2012). Moreover, localized contraction of smooth muscles has recently been proposed to generate the force that drives intramural periarterial drainage of $\mathrm{A} \beta$ (Aldea et al., 2019). Astrocytes contribute to the formation of the basement membrane and have also been shown to take up A $\beta$ via LRP-1 (Basak et al., 2012). In addition, astrocytes are the main producers of apolipoprotein $\mathrm{E}$, which chaperones $\mathrm{A} \beta$ across the BBB (Bell et al., 2007). Therefore, it is possible that the combined loss of cholinergic innervation at each of these components contributes to the increased susceptibility of cortical vessels to the development of CAA. Further studies are needed to investigate this putative relationship in human brain tissues.

\section{DATA AVAILABILITY}

The datasets generated for this study are available on request to the corresponding author.

\section{ETHICS STATEMENT}

This study was carried out in accordance with the recommendations of the Animal Welfare and Ethics Research Boards at the Open University and the University of Southampton. The protocol was approved by the Home Office (PPL 70/8507; PPL 30/3095).

\section{AUTHOR CONTRIBUTIONS}

SN performed the experiments and data analysis. RC, IR and $\mathrm{CH}$ planned the experimental design. $\mathrm{SN}$ and $\mathrm{CH}$ wrote the manuscript.

\section{FUNDING}

This work was supported by funding from Alzheimer's Research UK (ARUK-PG2015-12). 


\section{ACKNOWLEDGMENTS}

We wish to thank the BRU staff at the Open University and the University of Southampton for assistance.

\section{REFERENCES}

Albargothy, N. J., Johnston, D. A., MacGregor-Sharp, M., Weller, R. O., Verma, A., Hawkes, C. A., et al. (2018). Convective influx/glymphatic system: tracers injected into the CSF enter and leave the brain along separate periarterial basement membrane pathways. Acta Neuropathol. 136, 139-152. doi: 10.1007/s00401-018-1862-7

Aldea, R., Weller, R. O., Wilcock, D. M., Carare, R. O., and Richardson, G. (2019). Cerebrovascular smooth muscle cells as the drivers of intramural periarterial drainage of the brain. Front. Aging Neurosci. 11:1. doi: 10.3389/fnagi.2019. 00001

Baeten, K. M., and Akassoglou, K. (2011). Extracellular matrix and matrix receptors in blood-brain barrier formation and stroke. Dev. Neurobiol. 71, 1018-1039. doi: 10.1002/dneu.20954

Basak, J. M., Verghese, P. B., Yoon, H., Kim, J., and Holtzman, D. M. (2012). Low-density lipoprotein receptor represents an apolipoprotein E-independent pathway of $\mathrm{A} \beta$ uptake and degradation by astrocytes. J. Biol. Chem. 287, 13959-13971. doi: 10.1074/jbc.M111.288746

Bell, R. D., Sagare, A. P., Friedman, A. E., Bedi, G. S., Holtzman, D. M., Deane, R., et al. (2007). Transport pathways for clearance of human Alzheimer's amyloid beta-peptide and apolipoproteins $\mathrm{E}$ and $\mathrm{J}$ in the mouse central nervous system. J. Cereb. Blood Flow Metab. 27, 909-918. doi: 10.1038/sj.jcbfm.9600419

Berger-Sweeney, J., Stearns, N. A., Murg, S. L., Floerke-Nashner, L. R., Lappi, D. A., and Baxter, M. G. (2001). Selective immunolesions of cholinergic neurons in mice: effects on neuroanatomy, neurochemistry and behavior. J. Neurosci. 21, 8164-8173. doi: 10.1523/JNEUROSCI.21-20-08164.2001

Birthelmer, A., Ehret, A., Amtage, F., Förster, S., Lehmann, O., Jeltsch, H., et al. (2003). Neurotransmitter release and its presynaptic modulation in the rat hippocampus after selective damage to cholinergic or/and serotonergic afferents. Brain Res. Bull. 59, 371-381. doi: 10.1016/s0361-9230(02)00930-9

Cavedo, E., Grothe, M. J., Colliot, O., Lista, S., Chupin, M., Dormont, D., et al. (2017). Reduced basal forebrain atrophy progression in a randomized donepezil trial in prodromal Alzheimer's disease. Sci. Rep. 7:11706. doi: 10.1038/s41598-017-09780-3

Chédotal, A., Cozzani, C., Faure Pierre, M., Hartman, B. K., and Hamel, E. (1994). Distinct choline acetyltransferase (ChAT) and vasoactive intestinal polypeptide (VIP) bipolar neurons project to local blood vessels in the rat cerebral cortex. Brain Res. 646, 181-193. doi: 10.1016/0006-8993(94)90076-0

Chen, B. R., Kozberg, M. G., Bouchard, M. B., Shaik, M. A., and Hillman, E. M. C. (2014). A critical role for the vascular endothelium in functional neurovascular coupling in the brain. J. Am. Heart Assoc. 3:e000787. doi: 10.1161/JAHA.114. 000787

Chen, L., Yin, D., Wang, T.-X., Guo, W., Dong, H., Xu, Q., et al. (2016). Basal forebrain cholinergic neurons primarily contribute to inhibition of electroencephalogram delta activity, rather than inducing behavioral wakefulness in mice. Neuropsychopharmacology 41, 2133-2146. doi: $10.1038 /$ npp.2016.13

Christov, A., Ottman, J., Hamdheydari, L., and Grammas, P. (2008). Structural changes in Alzheimer's disease brain microvessels. Curr. Alzheimer Res. 5, 392-395. doi: 10.2174/156720508785132334

Damasio, A. R., Graff-Radford, N. R., Eslinger, P. J., Damasio, H., and Kassell, N. (1985). Amnesia following basal forebrain lesions. Arch. Neurol. 42, 263-271. doi: 10.1001/archneur.1985.04060030081013

Emsley, J. G., and Macklis, J. D. (2006). Astroglial heterogeneity closely reflects the neuronal-defined anatomy of the adult murine CNS. Neuron Glia Biol. 2, 175-186. doi: 10.1017/S1740925x06000202

Engelhardt, B., Carare, R. O., Bechmann, I., Flügel, A., Laman, J. D., and Weller, R. O. (2016). Vascular, glial and lymphatic immune gateways of the central nervous system. Acta Neuropathol. 132, 317-338. doi: 10.1007/s00401016-1606-5

\section{SUPPLEMENTARY MATERIAL}

The Supplementary Material for this article can be found online at: https://www.frontiersin.org/articles/10.3389/fnagi. 2019.00172/full\#supplementary-material

Farkas, E., and Luiten, P. G. (2001). Cerebral microvascular pathology in aging and Alzheimer's disease. Prog. Neurobiol. 64, 575-611. doi: 10.1016/s03010082(00)00068-x

Fine, A., Hoyle, C., Maclean, C. J., Levatte, T. L., Baker, H. F., and Ridley, R. M. (1997). Learning impairments following injection of a selective cholinergic immunotoxin, ME20.4 IgG-saporin, into the basal nucleus of meynert in monkeys. Neuroscience 81, 331-343. doi: 10.1016/s0306-4522(97) 00208-x

Francis, P. T., Palmer, A. M., Snape, M., and Wilcock, G. K. (1999). The cholinergic hypothesis of Alzheimer's disease: a review of progress. J. Neurol. Neurosurg. Psychiatry 66, 137-147. doi: 10.1136/jnnp.66.2.137

Garcia-Alloza, M., Gil-Bea, F. J., Diez-Ariza, M., Chen, C. P. L.-H., Francis, P. T., Lasheras, B., et al. (2005). Cholinergic-serotonergic imbalance contributes to cognitive and behavioral symptoms in Alzheimer's disease. Neuropsychologia 43, 442-449. doi: 10.1016/j.neuropsychologia.2004.06.007

Hamel, E. (2006). Perivascular nerves and the regulation of cerebrovascular tone. J. Appl. Physiol. 100, 1059-1064. doi: 10.1152/japplphysiol.00954.2005

Hamilton, N. B., Attwell, D., and Hall, C. N. (2010). Pericyte-mediated regulation of capillary diameter: a component of neurovascular coupling in health and disease. Front. Neuroenergetics 2:5. doi: 10.3389/fnene.2010.00005

Hamlin, A. S., Windels, F., Boskovic, Z., Sah, P., and Coulson, E. J. (2013) Lesions of the Basal Forebrain Cholinergic System in Mice Disrupt Idiothetic Navigation. PLoS One 8:e53472. doi: 10.1371/journal.pone.0053472

Hampel, H., Mesulam, M.-M., Cuello, A. C., Farlow, M. R., Giacobini, E., Grossberg, G. T., et al. (2018). The cholinergic system in the pathophysiology and treatment of Alzheimer's disease. Brain 141, 1917-1933. doi: 10.1093/brain/awy132

Hangya, B., Ranade, S. P., Lorenc, M., and Kepecs, A. (2015). Central cholinergic neurons are rapidly recruited by reinforcement feedback. Cell 162, 1155-1168. doi: 10.1016/j.cell.2015.07.057

Hawkes, C. A., Gatherer, M., Sharp, M. M., Dorr, A., Yuen, H. M., Kalaria, R., et al. (2013). Regional differences in the morphological and functional effects of aging on cerebral basement membranes and perivascular drainage of amyloid- $\beta$ from the Mouse Brain. Aging Cell 12, 224-236. doi: 10.1111/acel. 12045

Hawkes, C., Jhamandas, J. H., and Kar, S. (2005). Selective Loss of basa forebrain cholinergic neurons by 192 IgG-saporin is associated with decreased phosphorylation of ser glycogen synthase kinase-3B. J. Neurochem. 95, 263-272. doi: 10.1111/j.1471-4159.2005.03363.x

Hunter, C. L., Quintero, E. M., Gilstrap, L., Bhat, N. R., and Granholm, A.C. (2004). Minocycline protects basal forebrain cholinergic neurons from mu P75-saporin immunotoxic lesioning. Eur. J. Neurosci. 19, 3305-3316. doi: 10.1111/j.0953-816x.2004.03439.x

Iadecola, C. (2017). The neurovascular unit coming of age: a journey through neurovascular coupling in health and disease. Neuron 96, 17-42. doi: 10.1016/j. neuron.2017.07.030

Iliff, J. J., Wang, M., Liao, Y., Plogg, B. A., Peng, W., Gundersen, G. A., et al. (2012) A paravascular pathway facilitates CSF flow through the brain parenchyma and the clearance of interstitial solutes, including amyloid $\beta$. Sci. Transl. Med. 4:147ra111. doi: 10.1126/scitranslmed.3003748

Itakura, T., Yamamoto, K., Tohyama, M., and Shimizu, N. (1977). Central dual innervation of arterioles and capillaries in the brain. Stroke 8, 360-365. doi: 10.1161/01.str.8.3.360

Iturria-Medina, Y., Sotero, R. C., Toussaint, P. J., Mateos-Pérez, J. M., Evans, A. C. and Alzheimer's Disease Neuroimaging Initiative. (2016). Early role of vascular dysregulation on late-onset Alzheimer's disease based on multifactorial data-driven analysis. Nat. Commun. 7:11934. doi: 10.1038/ncomms 11934

Jack, C. R., Knopman, D. S., Jagust, W. J., Shaw, L. M., Aisen, P. S., Weiner, M. W., et al. (2010). Hypothetical model of dynamic biomarkers of the Alzheimer's 
pathological cascade. Lancet Neurol. 9, 119-128. doi: 10.1016/S14744422(09)70299-6

Kalaria, R. N., and Pax, A. B. (1995). Increased collagen content of cerebral microvessels in Alzheimer's disease. Brain Res. 705, 349-352. doi: 10.1016/0006-8993(95)01250-8

Kanekiyo, T., Liu, C.-C., Shinohara, M., Li, J., and Bu, G. (2012). LRP1 in brain vascular smooth muscle cells mediates local clearance of Alzheimer's AmyloidB. J. Neurosci. 32, 16458-16465. doi: 10.1523/JNEUROSCI.3987-12.2012

Kerbler, G. M., Hamlin, A. S., Pannek, K., Kurniawan, N. D., Keller, M. D., Rose, S. E., et al. (2013). Diffusion-weighted magnetic resonance imaging detection of basal forebrain cholinergic degeneration in a mouse model. Neuroimage 66, 133-141. doi: 10.1016/j.neuroimage.2012.10.075

Kitt, C. A., Höhmann, C., Coyle, J. T., and Price, D. L. (1994). Cholinergic innervation of mouse forebrain structures. J. Comp. Neurol. 341, 117-129. doi: 10.1002/cne.903410110

Kuznetsova, E., and Schliebs, R. (2013). $\beta$-amyloid, cholinergic transmission and cerebrovascular system-a developmental study in a mouse model of Alzheimer's disease. Curr. Pharm. Des. 19, 6749-6765. doi: 10.2174/13816128113199990711

Laursen, B., Mørk, A., Plath, N., Kristiansen, U., and Bastlund, J. F. (2013). Cholinergic degeneration is associated with increased plaque deposition and cognitive impairment in APPswe/PS1dE9 mice. Behav. Brain Res. 240, 146-152. doi: 10.1016/j.bbr.2012.11.012

Leanza, G. (1998). Chronic elevation of amyloid precursor protein expression in the neocortex and hippocampus of rats with selective cholinergic lesions. Neurosci. Lett. 257, 53-56. doi: 10.1016/s0304-3940(98)00744-7

Lecrux, C., Sandoe, C. H., Neupane, S., Kropf, P., Toussay, X., Tong, X. K., et al. (2017). Impact of altered cholinergic tones on the neurovascular coupling response to whisker stimulation. J. Neuroscience 37, 1518-1531. doi: 10.1523/ JNEUROSCI.1784-16.2016

Lehmann, O., Bertrand, F., Jeltsch, H., Morer, M., Lazarus, C., Will, B., et al. (2002). 5,7-DHT-induced hippocampal 5-HT depletion attenuates behavioural deficits produced by 192 IgG-saporin lesions of septal cholinergic neurons in the rat. Eur. J. Neurosci. 15, 1991-2006. doi: 10.1046/j.1460-9568.2002.02037.x

Li, X., Yu, B., Sun, Q., Zhang, Y., Ren, M., Zhang, X., et al. (2018). Generation of a whole-brain atlas for the cholinergic system and mesoscopic projectome analysis of basal forebrain cholinergic neurons. Proc. Natl. Acad. Sci. US A 115, 415-420. doi: 10.1073/pnas.1703601115

Lin, L., Georgievska, B., Mattsson, A., and Isacson, O. (1999). Cognitive changes and modified processing of amyloid precursor protein in the cortical and hippocampal system after cholinergic synapse loss and muscarinic receptor activation. Proc. Natl. Acad. Sci. U S A 96, 12108-12113. doi: 10.1073/pnas.96. 21.12108

Luiten, P. G., de Jong, G. I., Van der Zee, E. A., and van Dijken, H. (1996). Ultrastructural localization of cholinergic muscarinic receptors in rat brain cortical capillaries. Brain Res. 720, 225-229. doi: 10.1016/0006-8993(96) 00195-3

Magaki, S., Tang, Z., Tung, S., Williams, C. K., Lo, D., Yong, W. H., et al. (2018). The effects of cerebral amyloid angiopathy on integrity of the bloodbrain barrier. Neurobiol. Aging 70, 70-77. doi: 10.1016/j.neurobiolaging.2018. 06.004

Michalski, D., Hofmann, S., Pitsch, R., Grosche, J., and Härtig, W. (2017). Neurovascular specifications in the alzheimer-like brain of mice affected by focal cerebral ischemia: implications for future therapies. J. Alzheimers Dis. 59, 655-674. doi: 10.3233/JAD-170185

Morris, A. W. J., Carare, R. O., Schreiber, S., and Hawkes, C. A. (2014). The cerebrovascular basement membrane: role in the clearance of $\beta$-amyloid and cerebral amyloid angiopathy. Front. Aging Neurosci. 6:251. doi: 10.3389/fnagi. 2014.00251

Mulligan, S. J., and MacVicar, B. A. (2004). Calcium transients in astrocyte endfeet cause cerebrovascular constrictions. Nature 431, 195-199. doi: 10.1038/nature02827

Nelson, A. R., Kolasa, K., and McMahon, L. L. (2014). Noradrenergic sympathetic sprouting and cholinergic reinnervation maintains non-amyloidogenic processing of A $\beta$ PP. J. Alzheimers Dis. 38, 867-879. doi: 10.3233/JAD130608

Noumbissi, M. E., Galasso, B., and Stins, M. F. (2018). Brain vascular heterogeneity: implications for disease pathogenesis and design of in vitro blood-brain barrier models. Fluids Barriers CNS 15:12. doi: 10.1186/s12987018-0097-2

Owens, T., Bechmann, I., and Engelhardt, B. (2008). Perivascular spaces and the two steps to neuroinflammation. J. Neuropathol. Exp. Neurol. 67, 1113-1121. doi: 10.1097/NEN.0b013e31818f9ca8

Perry, E. K. (1980). The cholinergic system in old age and Alzheimer's disease. Age Ageing 9, 1-8. doi: 10.1093/ageing/9.1.1

Ramos-Rodriguez, J. J., Pacheco-Herrero, M., Thyssen, D., MurilloCarretero, M. I., Berrocoso, E., Spires-Jones, T. L., et al. (2013). Rapid $\beta$-amyloid deposition and cognitive impairment after cholinergic denervation in APP/PS1 mice. J. Neuropathol. Exp. Neurol. 72, 272-285. doi: 10.1097/NEN. 0b013e318288a8dd

Scheiderer, C. L., McCutchen, E., Thacker, E. E., Kolasa, K., Ward, M. K., Parsons, D., et al. (2006). Sympathetic sprouting drives hippocampal cholinergic reinnervation that prevents loss of a muscarinic receptordependent long-term depression at CA3-CA1 synapses. J. Neurosci. 26, 3745-3756. doi: 10.1523/JNEUROSCI.5507-05.2006

Schmitz, T. W., Nathan Spreng, R., and Alzheimer's Disease Neuroimaging Initiative. (2016). Basal forebrain degeneration precedes and predicts the cortical spread of Alzheimer's pathology. Nat. Commun. 7:13249. doi: $10.1038 /$ ncomms 13249

Shepro, D., and Morel, N. M. (1993). Pericyte physiology. FASEB J. 7, 1031-1038. doi: 10.1096/fasebj.7.11.8370472

Shi, Y.-F., Han, Y., Su, Y.-T., Yang, J.-H., and Yu, Y.-Q. (2015). Silencing of cholinergic basal forebrain neurons using archaerhodopsin prolongs slow-wave sleep in mice. PLOS One 10:e0134421. doi: 10.1371/journal.pone.01 30130

Steininger, T. L., Wainer, B. H., Klein, R., Barbacid, M., and Palfrey, H. C. (1993). High-affinity nerve growth factor receptor (Trk) immunoreactivity is localized in cholinergic neurons of the basal forebrain and striatum in the adult rat brain. Brain Res. 612, 330-335. doi: 10.1016/0006-8993(93)91681-h

Thal, D. R., Griffin, W. S. T., de Vos, R. A. I., and Ghebremedhin, E. (2008). Cerebral amyloid angiopathy and its relationship to Alzheimer's disease. Acta Neuropathol. 115, 599-609. doi: 10.1007/s00401-008-0366-2

Thorin-Trescases, N., de Montgolfier, O., Pinçon, A., Raignault, A., Caland, L., Labbé, P., et al. (2018). Impact of pulse pressure on cerebrovascular events leading to age-related cognitive decline. Am. J. Physiol. Heart Circ. Physiol. 69 , H1214-H1224. doi: 10.1152/ajpheart.00637.2017

Tong, X. K., and Hamel, E. (1999). Regional cholinergic denervation of cortical microvessels and nitric oxide synthase-containing neurons in Alzheimer's disease. Neuroscience 92, 163-175. doi: 10.1016/s0306-4522(98) 00750-7

Toribatake, Y., Tomita, K., Kawahara, N., Baba, H., Ohnari, H., and Tanaka, S. (1997). Regulation of vasomotion of arterioles and capillaries in the cat spinal cord: role of $\alpha$ actin and endothelin-1. Spinal Cord 35, 26-32. doi: 10.1038/sj. sc. 3100348

van der Staay, F. J., Raaijmakers, W. G., Lammers, A. J., and Tonnaer, J. A. (1989). Selective fimbria lesions impair acquisition of working and reference memory of rats in a complex spatial discrimination task. Behav. Brain Res. 32, 151-161. doi: 10.1016/s0166-4328(89)80081-6

Vaucher, E., and Hamel, E. (1995). Cholinergic basal forebrain neurons project to cortical microvessels in the rat: electron microscopic study with anterogradely transported phaseolus vulgaris leucoagglutinin and choline acetyltransferase immunocytochemistry. J. Neurosci. 15, 7427-7441. doi: 10.1523/jneurosci.1511-07427.1995

Vinters, H. V. (1987). Cerebral amyloid angiopathy. A critical review. Stroke 18, 311-324. doi: 10.1161/01.STR.18.2.311

Vinters, H. V., and Gilbert, J. J. (1983). Cerebral amyloid angiopathy: incidence and complications in the aging brain. II. The distribution of amyloid vascular changes. Stroke 14, 924-928. doi: 10.1161/01.str.14.6.924

Whitehouse, P. J., Price, D. L., Struble, R. G., Clark, A. W., Coyle, J. T., and Delon, M. R. (1982). Alzheimer's disease and senile dementia: loss of neurons in the basal forebrain. Science 215, 1237-1239. doi: 10.1126/science.70 58341

Willis, C. L., Ray, D. E., Marshall, H., Elliot, G., Evans, J. G., and Kind, C. N. (2006). Basal forebrain cholinergic lesions reduce heat shock protein 72 response but not pathology induced by the NMDA antagonist MK-801 in the rat cingulate cortex. Neurosci. Lett. 407, 112-117. doi: 10.1016/j.neulet.2006.08.020 
Wu, H., Williams, J., and Nathans, J. (2014). Complete morphologies of basal forebrain cholinergic neurons in the mouse. Elife 3:e02444. doi: 10.7554/eLife. 02444

Wyss-Coray, T., Lin, C., Sanan, D. A., Mucke, L., and Masliah, E. (2000). Chronic overproduction of transforming growth factor-betal by astrocytes promotes Alzheimer's disease-like microvascular degeneration in transgenic mice. Am. J. Pathol. 156, 139-150. doi: 10.1016/s0002-9440(10)64713-x

Yeo, T. T., Chua-Couzens, J., Butcher, L. L., Bredesen, D. E., Cooper, J. D., Valletta, J. S., et al. (1997). Absence of P75NTR causes increased basal forebrain cholinergic neuron size, choline acetyltransferase activity and target innervation. J. Neurosci. 17, 7594-7605. doi: 10.1523/JNEUROSCI.17-2007594.1997

Zhang, Y., Jiang, Y. Y., Shao, S., Zhang, C., Liu, F. Y., Wan, Y., et al. (2017). Inhibiting medial septal cholinergic neurons with DREADD alleviated anxiety-like behaviors in mice. Neurosci. Lett. 638, 139-144. doi: 10.1016/j. neulet.2016.12.010
Zócalo, Y., Bia, D., Cabrera-Fischer, E. I., Wray, S., Galli, C., and Armentano, R. L. (2013). Structural and functional properties of venous wall: relationship between elastin, collagen and smooth muscle components and viscoelastic properties. ISRN Physiol. 2013, 1-9. doi: 10.1155/2013/906031

Conflict of Interest Statement: The authors declare that the research was conducted in the absence of any commercial or financial relationships that could be construed as a potential conflict of interest.

Copyright (c) 2019 Nizari, Carare, Romero and Hawkes. This is an open-access article distributed under the terms of the Creative Commons Attribution License (CC BY). The use, distribution or reproduction in other forums is permitted, provided the original author(s) and the copyright owner(s) are credited and that the original publication in this journal is cited, in accordance with accepted academic practice. No use, distribution or reproduction is permitted which does not comply with these terms. 